\section{Effects of explicit instruction in previewing, thinking aloud, and text structure on Egyptian University students' reading ability}

\author{
Abdel-Moety, Doha \\ Tanta University, Faculty of Education, Egypt (D.mahmoud@edu.tanta.edu.eg)
}

Received: 5 March 2013

Available Online: 27 October 2013

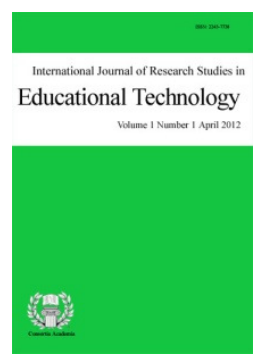

ISSN: $2243-7738$ Online ISSN: 2243-7746

Accepted: 24 October 2013

\title{
Abstract
}

The present study examines the effect of explicit instruction in three selective reading strategies on reading comprehension in English as a foreign language (EFL). The study addresses the following questions: A) Does explicit instruction in text structure help students identify discourse organization patterns? B) Does explicit instructional reading strategy in EFL develop reading comprehension? C) Is there a direct correlation between discourse organization knowledge and reading development? D) Does text structure knowledge develop EFL reading comprehension? Participants in the study are 60 first year Egyptian University students studying English as a foreign language. Results of the study indicated that knowledge of discourse organization patterns and reading strategies developed students' reading comprehension. They also showed that the students who were trained in text organization outperformed those who did not receive similar training. Moreover, the results revealed a statistically significant and positive correlation between text structure knowledge and reading comprehension. Finally, the paper provides suggestions for further research and implications for teachers and learners of English as a foreign language.

Keywords: reading strategy use; text organization; developing reading comprehension; content and formal schema; English as a foreign language. 


\section{Effects of explicit instruction in previewing, thinking aloud, and text structure on Egyptian University students' reading ability}

\section{Introduction}

The study of reading comprehension skills has been of interest to many researchers. Those researchers have noticed that reading comprehension skills are essential for students in order to be efficient readers. They have also shown that there are differences between good and poor readers. For example, Zimmerman and Hutchins (2003) observe that good readers can distinguish important information from unimportant one. Moreover, they can identify key ideas in texts when they read. In contrast, poor readers encounter difficulty in determining what is important in a text (Harvey and Goudvis, 2007). This difficulty may be due to a variety of factors including insufficient reading strategy instruction (Carrell, 1998). Thus, there has been a considerable number of investigations which have shown a positive relationship between reading strategy use and reading comprehension. Yet, Guthrie (1996) notes that most researchers study a single strategy rather than conducting a long term study of multiple strategies. Moreover, Alsamadani (2009) observes a lack of empirical investigations comparing EFL learners who use reading strategies with those who do not. In Addition, Lien (2011, p. 207) asserts that "there is a need for more research that focuses on the influence of reading strategies on foreign language reading proficiency",

Therefore, the present study is concerned with evaluating the effect of explicit instruction in three selective reading strategies on EFL Egyptian university students' reading ability. It focuses on using a combination of strategies rather than an individual strategy. These selected strategies together, it has been noted, were not used before in EFL contexts.

\section{Literature Review}

The reading process is "a complex, interactive and multifaceted process" (Esker, 1998). So, research on it has developed from diverse disciplines (Carlo and Sylvester, 1996) and has focused on different aspects of reading such as reading strategies, vocabulary development, the role of discourse organization and text structure, word recognition, and reading fluency. Yet, one of the most important areas of current research, according to Grabe (1991), is comprehension strategy training and text structure. The following section will provide a review of previous research dealing with strategy training and text structure, respectively.

\subsection{Comprehension strategy training studies}

Strategies "are actions selected deliberately to achieve particular goals" (Paris, Wasik \& Turner, 1991, p. 611). These goals, according to Grabe (1997), aim at improving comprehension whether in a first, second or foreign language. In other words, strategy training attempts to help readers become "strategic readers" so that they do not only know the strategy but also be able to use it automatically (Grabe and Stoller, 2002). Studies that are concerned with strategy training include Barnett (1988), Carrell, Pharis, and Liberto (1989), Chen and Graves (1995), Reid (2001), and Alsamadani (2009).

Barnett (1988) studied the effects of training students in the use of reading strategies on their reading performance. The subjects were university students studying French as a foreign language. They were divided into two groups: the first group received direct instruction while the second one followed a traditional curriculum. Barnett asked the subjects to perform three different tasks to see the performance of the two groups. The results showed that comprehension scores increased as strategy use scores increased and as perceived strategy use increased. 
In another study, Carrell, Pharis, and Liberto (1989) examined the effects of meta cognitive strategy training on improvements in L2 reading comprehension. The participants were U. S. university students from different language backgrounds. They were divided into two groups. One group had a course that included a metacognitive strategy use training while the other had a standard ESL course. The training was on the use of semantic mapping tasks and on the Experience-Text-Relationship (ETR) method. The aim was to model the use of metacognitive strategies so that the students could use these strategies later. Analyses of the results showed that the semantic training group improved in the tasks while the other group showed no improvement.

Similarly, Chen and Graves (1995) investigated the effects of the use of previewing and background knowledge on reading comprehension. The study included two hundred forty three Taiwanese university students. The students were divided into four groups. The first group received previews of the passages before reading. The second received background information before reading. The third received both previewing and background information about the passages and the fourth received nothing as it was the control group. Then, the students were asked to perform a post test. The results showed that the first three groups were better than the fourth one. Moreover, the previewing group and the combined group performed better than the background group. So, Chen and Graves concluded that preview is effective in reading development.

Reid (2001) studied the effect of Recovery techniques and individual reading strategies on middle school students. The participants were six ESL students with reading problems in English. Reid taught them some strategies that they can use such as focusing on word families, rerunning, using context clues, and stressing the necessity that a text must make sense. Then, a prior survey and a post one were conducted to see the development of students and the change in their views about reading. The results showed that students could use the strategies they learnt to attack unknown words and to make meaning of the print. In other words, they used the strategies as tools to improve reading. Moreover, the results indicated that the recovery techniques and the strategies had a positive effect on students' performance and on their attitudes about themselves. In addition, Reid found that their scores in the reading test were higher than their peers who do not participate in the study.

Gaverly, Nicholson, and Radcliffe (2004) conducted two studies in which they investigated the effect of teaching strategic reading to university students. The first study consisted of 36 first-year college students whose performance was less than the university freshmen population. The students received instruction based on authentic materials in the form of chapters from textbooks. The instruction aimed at teaching students to apply strategic reading. Then, their development was evaluated through a number of assessments. The results showed a significant progress in the students' performance in the pre test and the post test. The second study consisted of a control group and a treatment group. The treatment group included 51 students who received strategic reading instruction while the control group included 78 students who did not receive such instruction. The study examined long term effect of teaching strategic reading. The two groups performed a standardized test. The results revealed that students in the treatment group outperformed those in the control group even after several semesters.

More recently, Alsamadani (2009) examined the relationship between Saudi students' use of reading strategies and the effect of such use on reading comprehension. The study was conducted on one hundred forty EFL Saudi university students. The results indicated no significant/ linear relationship between reading strategy use and comprehension level of Saudi learners. Moreover, Alsamadani found that there were other factors which were perceived by students as having more effective contribution to their comprehension than reading strategies. These factors include "prior knowledge, enthusiasm for reading, time on task, purpose for reading, and vocabulary "(p. 3). So, he concluded that the use of reading strategies does not help Saudi students improve their EFL reading comprehension. This finding, it should be noted, contradicts other studies on reading strategies that emphasize the positive role of reading strategy use on reading comprehension. 


\subsection{Text structure studies}

The other important line of current research focuses on knowledge of discourse organization which is important for readers in a second language. Goldman and Rakestraw (2000, p. 323) observe that "knowledge of structure is clearly important in efficient and strategic processing of text". Similarly, Grabe (2002) remarks that discourse structure knowledge helps make expository texts understandable. Researchers have shown that discourse structure knowledge is important because texts are not a collection of sentences (Koda, 2005). Rather, they are structured carefully by authors so that each text has two functions. First, it conveys the semantic relationship among its elements. Second, it signals the "comparative importance of discrete ideas"(Koda, 2005.p 154). So, it is essential for readers to grasp these two functions in order to comprehend the text.

There are two remarkable studies on text structure and reading comprehension. The first study is that of Carrell (1985) in which she examined the effect of training readers to use text structure in comprehension. She investigated this effect in a study conducted on ESL university learners from diverse backgrounds. The study consisted of an experimental group and a control group. The two groups read the same texts. Yet, the experimental group was trained for one week to use top level organization structure while the other group focused on linguistic operations such as grammar exercises, sentence combining, discourse connectors, cohesion and vocabulary. The ESL learners performed a pre test and a post test. The results showed that students in the experimental group were more likely to use and recognize the organizational structures of texts than the control group. Moreover, their performance in the post test was better than the other group. This finding shows that training in the use of text structure strategies can help students improve comprehension.

The second study is that of Piyanukool (2004) in which she investigated the effects of teaching reading through discussion of text structure on Thai college students. The study lasted for ten weeks. Participants in the study were one hundred twenty six students. They were divided into two groups: a control group and an experimental group. The students in the experimental group were taught reading through discussion of text structure while students in the other group read texts silently. Then, the students in both groups performed a test for comprehension. The results of the study showed that there were not any differences between the two groups. In other words, the results indicated that teaching reading comprehension through discussion of text structure has no effect on students' reading ability. This result contradicts previous studies which prove that explicit text structure training improves text comprehension.

This review of previous studies on reading strategy use and text structure shows that research carried out on reading in EFL contexts is still limited. Furthermore, it indicates conflicting results concerning both reading strategy use and text structure in EFL settings. In addition, reading in English as a foreign language, particularly in Egypt, does not receive adequate attention. Therefore, the present study intends to examine the effects of the use of explicit instruction in three selective reading strategies, namely, previewing, thinking aloud, and text structure on EFL Egyptian university students' reading ability. In so doing, the study is unique since it combines reading strategies and text structure. Moreover, the context of the study, i., e. Egyptian EFL, is also new. The study addresses the following questions: A) Does explicit instruction in text structure help students identify discourse organization patterns? B) Does explicit instructional reading strategy in EFL develop reading comprehension? C) Is there a direct correlation between discourse organization knowledge and reading development? D) Does text structure knowledge develop EFL reading comprehension?

\section{The present study}

The present empirical study adopts an interactive approach to reading. This approach stresses the interactive role of participants. It views reading as a process of "acquiring information from a written or printed text and relating it to what [ a reader] already know[s] to construct a meaning for the text as a whole" (Eskey, 2002, p. 5). In addition, it emphasizes the role of strategy training and schema in reading development. Schema theory holds that a text does not carry meaning by itself. Rather, it gives directions to readers "as to how they should retrieve 
or construct meaning from their own, previously acquired knowledge" (Carrell and Eisterhold, 1998, p.76). Schema has certain slots that must be filled. Moreover, comprehension depends on readers' ability to recognize specific items in a text that fills those slots (Rumelhart, 1977). The present study uses the term schema, which as illustrated by Carrell (1983), includes formal schema and content schema. Formal schema means knowledge about the structural organization of different types of texts while content schema refers to knowledge about the content of the text.

\subsection{Participants}

Participants in the present study are first- year Egyptian female university students in the faculty of education studying English as a foreign language. They have been studying English for twelve years. Their English proficiency is at the intermediate level. The sample of the study consists of 60 students. The students are divided into two groups. The first group includes 30 students from the departments of biology, chemistry and physics. The second group includes 30 students from the departments of history, Arabic, and psychology. Although the departments are different, the students are at the same level. They form a homogeneous group. They study the same course under the title "English for non specialists". They join the faculty of Education to be teachers in different specializations with a specific proficiency in EFL.

The assignment of the students to either group was random to eliminate bias and to ensure validity of the results. Moreover, students at the beginning of the study do not know which group will receive the instruction. At the beginning of the semester, the first group received an introduction about reading strategies in general. Then, it was given explicit instruction in previewing, thinking aloud, and text structure. These strategies were selected because they represent both formal and content schemata. They were introduced in a sequential order. First, each strategy is explained in detail. Then, students were given time to practice it and to have a strong understanding of it before their introduction to the next one. Moreover, when introducing a new strategy, students were asked to combine the preceding one so that by the end of the semester, they were trained to use all three strategies together. On the other hand, the second group was not given any instruction in reading strategies. Rather, the students read the passages silently. They also used translation into their mother tongue, i. e., Arabic to facilitate reading comprehension. Then, they answered the comprehension questions of the passages they read. The study lasted for a full semester meeting twice per week.

\subsection{Measurements}

The study used the pre test/post test method. First, there was a pre- test to insure reasonable comparability. Then at the end of the semester, there was a post test given to the participants. The test consisted of two parts with two different types of questions: part one was in the form of exercises in identifying the rhetorical structure of selected paragraphs and part two was a reading test administered to measure the students' reading comprehension. The reading test was chosen according to the level of the participants. Part one included 12 short paragraphs followed by rhetorical structure questions about identifying the pattern in each paragraph whether it is description, cause and effect, comparison /contrast or problem /solution. In addition, each paragraph was followed by a number of sentences which students were asked to put in the appropriate paragraphs. Part two, on the other hand, consisted of a reading passage followed by 12 multiple-choice cloze questions. The test had to be answered in 60 minutes.

\subsection{Framework of the study}

The term "reading strategies" has various definitions. Those definitions vary according to the context in which this term is used, i., e., first, second or foreign language learning (Cohen, 1998). However, in the present study two important definitions are quite relevant. The first definition views strategies as "a set of abilities under conscious control of the reader" (Grabe and Stoller, 2002, p. 15). The second one is that adopted by Lien (2011) in which strategies are taken to be techniques used by readers in order to improve understanding and to solve 
Abdel-Moety, D.

difficulties encountered in reading. Previewing, thinking aloud, and text structure are selected in the present study as reading strategies.

Previewing, as Abraham (2002) states, is concerned with activating students' content schema. This strategy allows students skim through the text before they read. It provides students with a mental outline of the text that they read. In the study, students were trained to use previewing automatically whenever they read a new text. Similarly, thinking aloud, as Harvey and Goudvis (2007) indicate, teaches students to generate questions before, during, and after reading in order to construct meaning from what they read. In the present study, students were trained to pose possible questions about each passage before reading it. In class, students were asked to look for specific key features in each passage such as title, headlines and boldfaced words. Then, they provided questions that might be asked about the passage. During reading, students developed their ability in recognizing important points in passages and in confirming their understanding. This development has been achieved through students' engagement in class discussions about the reading passages. These discussions were in two forms: group discussions among students, and teacher- student discussions.

Text structure instruction, on the other hand, is concerned with formal schema. According to Grabe (1998), it is listed as one of a small number of important comprehension strategies with consistent results. Text structures are defined as "knowledge structures or basic rhetorical patterns in texts" (Grabe, 2001, p. 10). Those patterns are used by writers to achieve functional purposes that good readers can recognize. They lead readers to preferred interpretations. They include description, causation, comparison /contrast, and problem/solution. In the present study, group one students were taught that each passage/text follows a certain structure which should be identified from the beginning by the reader. Then, students were provided with key signal words for each pattern which will help them identify the purpose of the writer. Meyer's top level organization patterns, as presented by Carrell (1998) are used in the study. The patterns and the words that are typical clues of each organizational pattern are described in the following way:

\section{Time Order}

Words that are clues or signal words often used when writing in chronology, time sequence: first, next, last, in the end, days, dates, soon, later, finally, eventually, times, later on, in the meantime, afterwards, not long after, at the end, at last, right away, in the beginning.

\section{Comparison/Contrast}

Comparison/Contrast - information organized to show similarities, differences, advantages, disadvantages. Speaker's perspective may be neutral or may take a position.

Words that are clues or signal words of a comparison or contrast: but, different, however, like, contrary to, comparative forms (e.g., faster, slower), rather, on the contrary, as, in the same way, instead, yet, similarly, on the other hand.

\section{Collection of Descriptions}

Collection of descriptions - information organized by a simple listing of facts or ideas relating to the same topic.

Words that are clues or signal words of a collection of descriptions: some, others, many, a few, other, also, first, second, third, finally, in addition, lastly, all.

\section{Cause and Effect}

Cause and effect - information organized by showing the cause or causes of an event or situation, of the effects of some event or situation, or both.

Words that are clues or signal words of a cause/effect pattern: result, cause, effect, lead to, due to, 
consequently, because of, create, become, come out.

(Carrell, 1998, p. 250)

\subsection{Data Analysis}

The test was collected. Then, students' answer sheets were corrected and statistical analysis was run. Descriptive statistics provided mean, standard deviation, and P-value for participants' scores. Computation of Pearson's product-moment correlation coefficient was employed to indicate whether any statistically significant correlation existed between question one and question two of the test in both groups.

\section{Results and Discussion}

A. Does explicit instruction in text structure help students identify discourse organization patterns?

Question 1 in the test aimed at measuring students' ability to identify discourse organization patterns in different paragraphs. Results indicated that there were considerable differences between the two groups as regard discourse organization knowledge. Students in group 1 outperformed those in group 2. Table 1 provides a comparison between group 1 and group 2 as regard question 1.

Table 1

Comparison between group I and group II as regard QI

\begin{tabular}{rrrrrrrrr}
\hline & & & & & Q1 & & T-test \\
\hline & & & Range & Mean & \pm & SD & t & P-value \\
Group I & 15.000 & - & 40.000 & 31.833 & \pm & 7.711 & & \\
Group II & 0.000 & - & 25.000 & 17.333 & \pm & 5.683 & & $<0.001 *$ \\
\hline
\end{tabular}

As table 1 shows the mean for group 1 was 31.833 while the mean in group 2 was 17.333 . This finding demonstrates that students who received explicit instruction in rhetorical organization patterns had no difficulty in identifying them. They used graphic organizers to help them recognize the structure of texts. They also used the clues taught to them such as words which signal time order, those that signal comparison, and those used for causation effectively. In contrast, students who received no instruction could not distinguish the four organizational patterns, i., e., description, comparison/contrast, problem/solution, and causation correctly. For example, in two paragraphs from part 1 in the test, group 1 students used the signal words of a comparison /contrast such as "although, but, while, and both" and those that signal a collection of descriptions such as "many, first, and finally" to identify the pattern while students in group 2 could not. In addition, the results showed that group two students have no idea about the patterns. So, they chose the patterns randomly as they indicated during the test.

This result demonstrated that the techniques taught to the students in group 1 were quite helpful in identifying the organizational patterns. In other words, when students become aware of the rhetorical structures of texts, they identify them correctly. Moreover, students showed that they know the strategy and that they could use it strategically.

B. Does explicit instructional reading strategy in EFL develop reading comprehension?

As for the second question, a comparison between the results of the students in the two groups was made. Results of this comparison showed that there were remarkable differences in the performance of the two groups. Group 1 students were better than those of group 2. The following table shows these differences in the performance of the students as regard Q2. 
Abdel-Moety, D.

Table 2

Comparison between group I and group II as regard $Q 2$

\begin{tabular}{ccccccccc}
\hline & \multicolumn{9}{c}{ Q2 } & & \multicolumn{2}{c}{ T-test } \\
\hline & & Range & & Mean & \pm & SD & t & P-value \\
Group I & 21.000 & - & 45.000 & 35.800 & \pm & 5.623 & & $<0.001^{*}$ \\
Group II & 12.000 & - & 36.000 & 26.467 & \pm & 5.538 & & \\
\hline
\end{tabular}

The table shows that the mean for group1 students is 35.800 while that for group 2 students is 26.467. This result can be interpreted with regard to the three reading strategies which group 1 students were trained to use while group 2 students were not. That is students in group 1 applied the reading strategies they learnt. This application led to a better understanding of the reading comprehension questions. In contrast, students in group 2 did not apply reading strategies. So, they encountered difficulty in understanding the passage and/ or the comprehension questions of the test. Consequently, their scores in the reading comprehension test were low. This finding is similar to that of Sheorey and Mokhtari (2001) who note that when readers are not aware of certain strategies, they will not use them.

This result concerning scores in the reading comprehension test shows the effectiveness of the three selected strategies applied in the study. It indicates that training students in previewing, thinking aloud and text structure improves EFL students' reading ability. So, it can be concluded that activating background knowledge through previewing and thinking aloud and increasing students' awareness of rhetorical organization could enhance reading comprehension.

The comparison of the two groups as regard total scores of the test also revealed varieties in the two groups. Group 1 students were better than group 2. This better performance is due to their ability to identify the purpose and the form of the text. This ability is achieved through text structure strategy. Moreover, they could activate their background knowledge about the text and generate questions while reading through the use of previewing and thinking aloud strategies. This result is provided in the following graph which shows how total scores of the test were higher in group 1 than those in group 2.

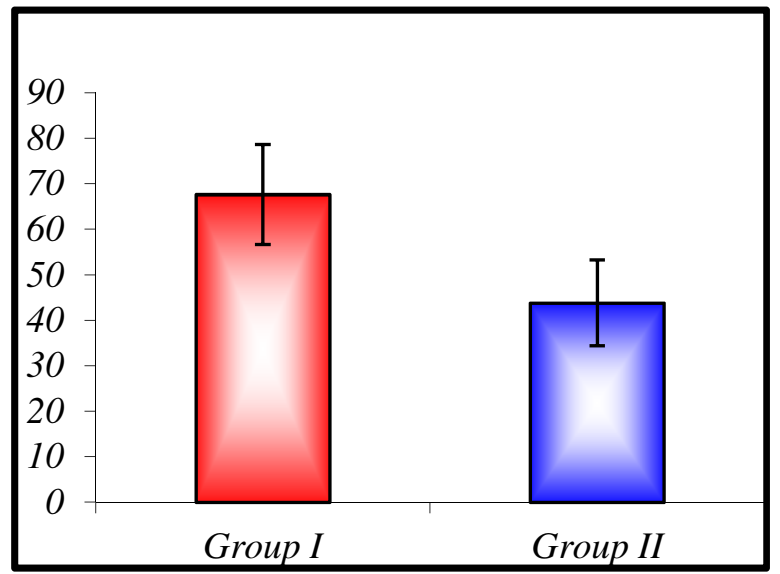

Graph 1. Comparison between Group 1 and Group 2 as regard total scores of the test

This finding agrees with Sheorey and Mokhtari (2001) who observe that good readers possess knowledge of reading strategies. It is also in line with Song (1998) and Gibson (2009) who note that a strategy based reading instruction is an effective way for improving reading comprehension. Moreover, this result is similar to that of Carrell (1985) and Carrell, Pharis, and Liberto (1989) who found that non- proficient readers do not obtain knowledge about reading strategies and that strategy instruction can help readers overcome reading difficulties. 
However, this result contrasts with that of Alsamadani (2009) who found that reading strategy use did not help Saudi students improve their EFL reading comprehension.

The study also applies an analysis of Pearson's correlation coefficient between Q1 and Q2 in both groups in order to provide an answer for the following question: C) is there a direct correlation between discourse organization knowledge and reading development? The following graph presents the results of this analysis.

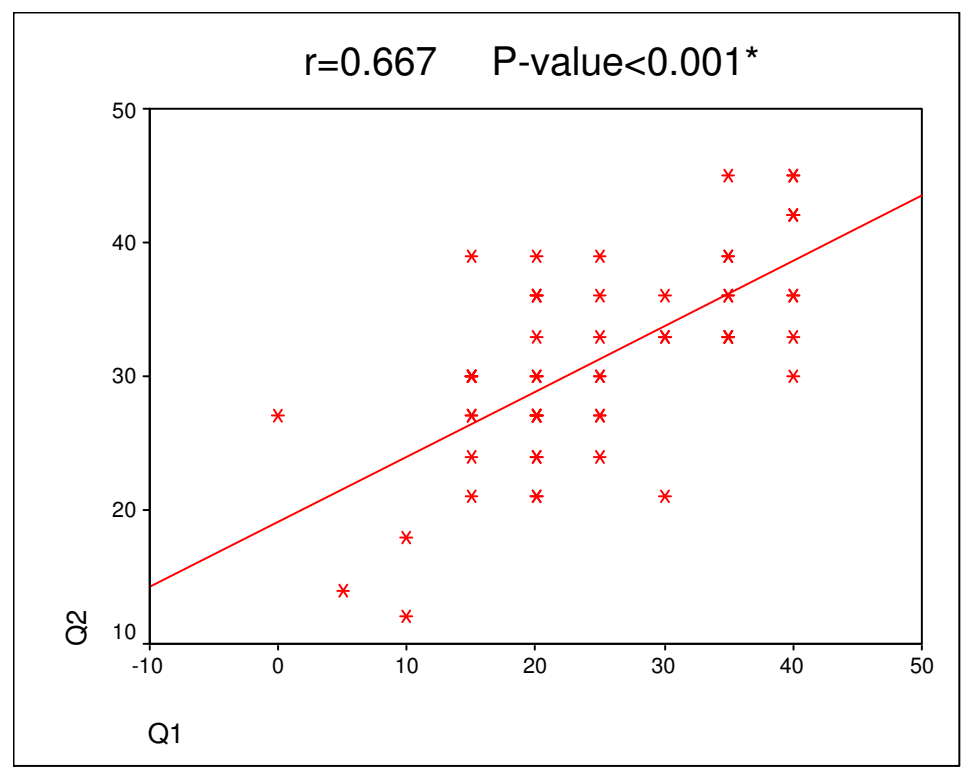

Graph 2. Scatter plot correlation co efficient between Q1 and Q2

As graph 2 shows, the correlation is $[\mathrm{r}=0.667$, P-value was $<0.001 *]$, which reveals a statistically significant and positive correlation at 0.05 level of significance. This finding means that a statistically significant and positive relationship exists between students' knowledge of discourse organization patterns and their overall reading proficiency level. In other words, there is a strong association between the two variables measured. This finding can lead to an answer for the last question in the study, i., e., D) Does text structure knowledge develop reading comprehension? We can say that an awareness of text structure could be a predictor of students' reading comprehension test scores. In other words, text structure knowledge is one of the causes of the differences found in the performance of the two groups as the pre test at the beginning of the study revealed similarity in the level of the two groups. So, we can say that text structure knowledge developed students' reading ability in the present study conducted on EFL Egyptian university students.

This finding is in line with Pearson and Fielding's (1991) observation that "any sort of systematic attention to clues that reveal $[\mathrm{s}]$ how the authors attempt to relate ideas to one another or any sort of systematic attempt to impose structure on a text... facilitates comprehension ..." (Pearson \& Fielding (1991) as cited in Grabe, 2002, p. 10). It also agrees with Grabe (1997) who states that when students are encouraged to predict, clarify, summarize, and note text organization, their reading ability is improved. However, the finding of the present study differs from that of Piyanukool (2001) who found no difference in the reading comprehension ability of students taught reading through discussion of text structures and that of students taught reading without discussion of text structures.

\section{Conclusion}

The present study investigates the effect of explicit instruction in three selective reading strategies, namely, previewing, thinking aloud, and text structure on EFL reading comprehension. Results of the study can be summarized in the following points: first, students who had no idea about discourse organization patterns and 
Abdel-Moety, D.

reading strategies encountered difficulty in reading comprehension; second, knowledge of discourse organization patterns and reading strategy use developed students' reading ability; third, students who received explicit instruction in previewing, thinking aloud, and text structure had better comprehension than those who did not receive such instruction; and fourth, there is a significant positive correlation between knowledge of discourse organization patterns and reading comprehension proficiency.

In spite of these findings, there appear two limitations in the study. First, the number of participants in the study was small. Second, the study does not have follow up techniques to ensure that students will continue using the strategies they learned in their subsequent reading courses and that their development in reading comprehension will be permanent.

\subsection{Suggestions and implications}

The present study stresses the effectiveness of explicit reading strategy instruction in EFL settings. It also draws the attention toward the importance of text structure instruction in developing EFL reading comprehension. Similar investigations can be adapted to other aspects of text structure such as genre features. Moreover, future studies can focus on different methods for explicit text structure to find out the most effective one in developing reading comprehension. The study can also be replicated using other combinations of the reading strategies and/or the same combination with elementary, pre-intermediate or advanced EFL students. Such studies can lead to a better understanding of the effect of explicit instruction in reading strategies on developing students' reading ability.

The study has also some implications for EFL teaching and teachers. First, reading courses, particularly in Egypt, should focus on developing an awareness of the structure of written texts in their learning goals. Reading comprehension texts can be chosen so that they include different structural patterns. These patterns can be selected by instructors according to the instructional purposes. Second, discourse organizational patterns can be taught to teachers in a training workshop. This training will be effective since it will enable teachers to focus on text structure in teaching. Their goal will be to draw students' attention toward understanding the purpose of writers of different texts. This goal can be achieved through students' extensive practice in identifying different organizational patterns. Third, the present study has shown that active participation of students is important in reading. That is, when students were engaged in discussions about the texts, they had a better understanding of them. So, classroom reading tasks can be oriented to ensure students' active participation. Finally, Reading courses can adopt the reading strategy training method as an alternative to the traditional method which depends on vocabulary and grammar. EFL teachers can order the strategies and train students to use them automatically. Such use will ensure EFL reading comprehension development.

\section{References}

Abraham, P. (2002). Skilled reading: Top-down, bottom-up. Field Notes, 10(2), 1-6. Retrieved June 15, 2011, from http://www.sabes.org/resources/publications/index.htm

Alsamadani, H. A. (2009). The relationship between Saudi EFL college-level students' use of reading strategies and their EFL reading comprehension. Unpublished doctoral dissertation. Retrieved June 15, 2011, from http://etd.ohiolink.edu

Barnett, M. A. (1988). Reading through context: How real and perceived strategy use affects comprehension. Modern Language Journal, 72(2), 150-162. http://dx.doi.org/10.1111/j.1540-4781.1988.tb04177.x

Carrell, P. L. (1983). Three components of background knowledge in reading comprehension. Language Learning, 32, 183-207. http://dx.doi.org/10.1111/j.1467-1770.1983.tb00534.x

Carrell, P. L. (1985). Facilitating ESL reading by teaching text structure. TESOL Quarterly, 19(4), 727-752. http://dx.doi.org/10.2307/3586673

Carrell, P. L. (1998). Introduction: Interactive approaches to second language reading. In P.L. Carrell, J. Devine, \& D. E. Eskey (Eds.), Interactive approaches to second language reading (pp. 1-7). Cambridge: 
Cambridge University Press.

Carrell, P. L. (1998). Interactive text processing: Implications for ESL second language reading classroom. In P. L. Carrell, J. Devine, \& D. E. Eskey (Eds.), Interactive approaches to second language reading (pp. 239-259). Cambridge: Cambridge University Press.

Carrell, P. L., \& Eisterhold, J. C. (1998). Schema theory and ESL reading pedagogy. In P. L. Carrell, J. Devine, \& D. E. Eskey (Eds.), Interactive approaches to second language reading (pp. 73-92). Cambridge: Cambridge University Press.

Carrell, P. L., Pharis, B. G., \& Liberto, J. C. (1989). Metacognitive strategy training for ESL reading. TESOL Quarterly, 23(4), 647-678. http://dx.doi.org/10.2307/3587536

Carlo, M. S., \& Sylvester, E. S. (1996). Adult second language reading research: How may it inform assessment and instruction? Philadelphia: National center on adult literacy.

Caverly, D. C., Nicholson, S. A., \& Radcliffe, R. (2004). The effectiveness of strategic reading instruction for college developmental readers. Journal of College Reading and Learning, 35(1), 25-49.

Chen, H. C., \& Graves, M. F. (1995). Effects of previewing and providing background knowledge on Taiwanese college students' comprehension of American short stories. TESOL Quarterly, 29, 663-686. http://dx.doi.org/10.2307/3588168

Cohen, A. (1998). Strategies in learning and using a second language. London: Longman.

Eskey, D. E. (1998). Holding in the bottom: An interactive approach to the language problems of second language readers. In P. L. Carrell, J. Devine, \& D. E. Eskey (Eds.), Interactive approaches to second language reading (pp. 93-100). Cambridge: Cambridge University Press.

Eskey, D. E. (2002). Reading and the teaching of L2 reading. TESOL Journal, 11(1), 5-9.

Garner, R. (1987). Training students to use strategies. In R. Garner (Ed.), Metacognition and Reading Comprehension (pp. 105-122). Norwood, NJ: Ablex.

Gibson, K. D. (2009). Teachers' perceptions of strategy based reading instruction for reading comprehension. Retrieved May 15, 2011, from http://eric.ed.gov/?q=teachers+perceptions+of+strategy+based+reading+instruction+for+reading+comp rehension+site $\% 3 \mathrm{Ahttp} \% 3 \mathrm{~A} \% 2 \mathrm{~F} \% 2 \mathrm{Fwww}$.eric.ed.gov\&ft=on

Goldman, S. R., \& Rakestraw, J. R. (2000). Structural aspects of constructing meaning from text. In M. L. Kamil, P. Mosentthal, \& P. D. Pearson (Eds.), Handbook of reading research (vol. 3, pp. 311-335). Mahwah, NJ: Lawrence Erlbaum.

Grabe, W. (1991). Current developments in second language reading research. TESOL Quarterly, 25(3), $375-406$. http://dx.doi.org/10.2307/3586977

Grabe, W. (1997). Discourse analysis and reading instruction. In T. Miller (Ed.), Functional approaches to written texts: Classroom applications (pp. 2-15). Washington, DC: USIA.

Grabe, W. (1998). Reassessing the term "interactive". In P. L. Carrell, J. Devine, \& D. E. Eskey (Eds.), Interactive approaches to second language reading (pp. 56-70). Cambridge: Cambridge University Press.

Grabe, W. (2001). Reading-writing relations: Theoretical perspectives and instructional practices. In D. Belcher \& A. Hirvela (Eds.), Linking literacies: Perspectives on L2 reading-writing connections (pp. 15-47). Ann Arbor: University of Michigan Press.

Grabe, W. (2002). Using discourse patterns to improve reading comprehension. Retrieved November 27, 2010, from http://jalt-publications.org/proceedings/articles/220-jalt2002-proceedings-contents-listing

Grabe, W., \& Stoller, F. L. (2002). Teaching and researching reading. Harlow: Longman.

Guthrie, J. T. (1996). Educational contexts for engagement in literacy. The Reading Teacher, 49(6), 432-445.

Harvey, S., \& Goudvis, A. (2007). Strategies that work: Teaching comprehension for understanding and engagement (2nd ed.). Portland: Stenhouse Publishers.

Koda, K. (2005). Insights into second language reading: A cross-linguistic approach. Cambridge: Cambridge University Press. http://dx.doi.org/10.1017/CBO9781139524841

Lien, H. Y. (2011). EFL learners' reading strategy use in relation to reading anxiety. Language Education in Asia, 2(2), 199-212. http://dx.doi.org/10.5746/LEiA/11/V2/I2/A03/Lien 
Abdel-Moety, D.

Paris, S. G., Wasik, B. A., \& Turner, J. C. (1991). The development of strategic readers. In R. Barr, M. L. Kamil, P. Mosentthal, \& P. D. Pearson (Eds.), Handbook of reading research (vol. 2, pp. 604-640). Mahwah, NJ: Lawrence Erlbaum.

Pearson, P., \& Fielding, L. (1991). Comprehension instruction. In R. Barr, M. L. Kamil, P. Mosentthal, \& P. D. Pearson (Eds.), Handbook of reading research (vol. 2, pp. 815-860). New York: Longman.

Piyanukool, S. (2001). Effects of teaching reading through discussion of text structure. Unpublished doctoral dissertation. Retrieved January 15, 2012, from http://digital.library.unt.edu/search/?q=Effects+of+teaching+reading+through+discussion+of+text+stru cture \& $\mathrm{t}=$ fulltext

Reid, L. (2001). How does the use of reading recovery techniques and individualized reading strategies affect the reading skills of middle-school second language learners? Retrieved May 20, 2011, from http://eric.ed.gov/?q=How+does+the+use+of+reading+recovery+techniques+and+individualized+readi $\underline{\text { ng+strategies+affect+the+reading+skills }+ \text { of }+ \text { middle-school+second+language }+ \text { learners } \% 3 \mathrm{f} \& \mathrm{ft}=\mathrm{on} \& \mathrm{id}}$ $=\mathrm{ED} 456646$

Rumelhart, D. (1977). Toward an interactive model of reading. In S. Dornic (Ed.), Attention and performance (Vol. VI., pp. 573-603). New York: Academic Press.

Sheorey, R., \& Mokhtari, K. (2001). Differences in the metacognitive awareness of reading strategies among native and non-native readers. System, 29(4), 431-449. http://dx.doi.org/10.1016/S0346-251X(01)00039-2

Smith, F. (1971). Understanding reading: A psycholinguistic analysis of reading and learning to read. New York: Holt, Rinehart and Winston.

Song, M. (1998). Teaching reading strategies in an ongoing EFL university reading classroom. Asian Journal of English Language Teaching, 8, 41-54.

Stanovich, K. (1980). Toward an interactive-compensatory model of individual differences in the development of reading fluency. Reading Research Quarterly, 16, 32-71. http://dx.doi.org/10.2307/747348

Zimmerman, S., \& Hutchins, C. (2003). Seven keys to comprehension: How to help your kids read it and get it! New York: Three Rivers Press. 